OPEN ACCESS

Edited by:

Wei Guo,

Institute of Zoology (CAS), China

Reviewed by:

Chuan Ma,

Chinese Academy of Agricultural

Sciences, China

Jagadish S. Bentur

Agri Biotech Foundation, India

*Correspondence:

Wen-Xia Zhao

zhaowx9501@126.com

Specialty section:

This article was submitted to

Epigenomics and Epigenetics,

a section of the journal

Frontiers in Genetics

Received: 10 January 2020

Accepted: 27 March 2020

Published: 17 April 2020

Citation:

Yao $Y-X$, Shang $X-P$, Yang J, Lin $R$-Z, Huai $W-X$ and Zhao $W-X$

(2020) Genetic Variation May Have

Promoted the Successful Colonization

of the Invasive Gall Midge,

Obolodiplosis robiniae, in China.

Front. Genet. 11:387.

doi: $10.3389 /$ fgene.2020.00387

\section{Genetic Variation May Have Promoted the Successful Colonization of the Invasive Gall Midge, Obolodiplosis robiniae, in China}

\author{
Yan-Xia Yao, Xing-Pu Shang, Jun Yang, Ruo-Zhu Lin, Wen-Xia Huai and Wen-Xia Zhao* \\ Key Laboratory of Forest Protection of National Forestry and Grassland Administration/Research Institute of Forest Ecology, \\ Environment and Protection, Chinese Academy of Forestry, Beijing, China
}

Invasive species often cause serious economic and ecological damage. Despite decades of extensive impacts of invasives on bio-diversity and agroforestry, the mechanisms underlying the genetic adaptation and rapid evolution of invading populations remain poorly understood. The black locust gall midge, Obolodiplosis robiniae, a highly invasive species that originated in North America, spread widely throughout Asia and Europe in the past decade. Here, we used 11 microsatellite DNA markers to analyze the genetic variation of 22 O. robiniae populations in China (the introduced region) and two additional US populations (the native region). A relatively high level of genetic diversity was detected among the introduced populations, even though they exhibited lower diversity than the native US populations. Evidence for genetic differentiation among the introduced Chinese populations was also found based on the high Fst value compared to the relatively low among the native US populations. Phylogenetic trees, structure graphical output, and principal coordinate analysis plots suggested that the Chinese 0 . robiniae populations (separated by up to 2,540 km) cluster into two main groups independent of geographical distance. Genetic variation has been observed to increase rapidly during adaptation to a new environment, possibly contributing to population establishment and spread. Our results provide insights into the genetic mechanisms underlying successful invasion, and identify factors that have contributed to colonization by an economically important pest species in China. In addition, the findings improve our understanding of the role that genetic structure plays during invasion by $O$. robiniae.

Keywords: genetic diversity, genetic differentiation, genetic structure, population colonization, invasion success

\section{INTRODUCTION}

Obolodiplosis robiniae (Haldeman, 1847) (Diptera: Cecidomyiidae) is a North American species of gall midge that has recently been extensively introduced throughout Asia and Europe (CABI/EPPO, 2011) and is continuously expanding its range (Cierjacks et al., 2013; Stalazs, 2014; Badmin, 2016; Kostro-Ambroziak and Mieczkowska, 2017). It is specifically associated with host plants from 
the genus Robinia (Fabaceae) (Stalazs, 2014). Its main host is Robinia pseudoacacia although it is occasionally found on $R$. pseudoacacia cv. 'Frisia' (Badmin, 2016). The gall midge causes leaf rolling and premature leaf shedding, resulting in the deterioration of the host and increased susceptibility to other pests, including wood borers such as longhorn beetles (Yang et al., 2006).

Obolodiplosis robiniae was first recorded in China (Qinhuangdao City, Hebei Province) in 2004 (Yang et al., 2006) and has since spread extensively. Its primary host (R. pseudoacacia) has been planted extensively across China, and $O$. robiniae is now found in most of these areas (Shang et al., 2015a). Chinese O. robiniae populations may produce between four and six generations per year (Wang, 2009; Mu et al., 2010; Shao et al., 2010; Liu, 2014), which is significantly higher than the rate in regions beyond China. For example, O. robiniae produces three to four generations per year in Italy (Duso et al., 2005) and Serbia (Mihajlovic et al., 2008), and a maximum of three generations per year in Korea (Lee et al., 2009).

Genetic diversity and population structure are important factors affecting the colonization of invasive species (Amouroux et al., 2013; Horst and Lau, 2015; Zhao et al., 2015). Invasive species often exhibit low genetic diversity during founding events, as new habitats are typically colonized by only a few individuals, representing a small proportion of the allelic diversity present in the source population (Nei et al., 1975; Tsutsui et al., 2003). However, when the founding individuals originate from multiple source populations, the genetic diversity of the founder population can be relatively high (Davis, 2009). This can contribute to invasion success by facilitating local adaptation to new environments and increasing new trait diversity (Facon et al., 2006). Besides, the invaders can rapidly evolve in isolation from other individuals of the same species when they were introduced into the new environments (Lee, 2002; Launey et al., 2010).

DNA-based molecular markers have been extensively used to examine the genetic diversity and population structure of a wide range of species. Microsatellite DNA markers (simple sequence repeats, SSRs) are suitable for routine genetic diversity analyses (Varshney et al., 2007; Kong et al., 2014; Kim et al., 2017), as they are ubiquitous among eukaryotes (Sharma et al., 2007), co-dominantly inherited, and highly polymorphic (Zong et al., 2015). Moreover, microsatellite analysis can yield valid results and improved phylogenetic trees compared to analyses involving other molecular markers (Schemerhorn et al., 2015). Due to their feasibility and practicality, microsatellite markers have been widely used in population genetics and ecological studies of various insects (Bonizzoni et al., 2000; MezghaniKhemakhem et al., 2012; Anjos et al., 2016; Retamal et al., 2016; Duan et al., 2017; Kim et al., 2017; Simonato et al., 2019), including several invasive gall midge species (Bentur et al., 2011; Amouroux et al., 2013).

Previously, Shang et al. (2015b) investigated the genetic variation among Chinese $O$. robiniae populations using a partial mitochondrial DNA cytochrome c oxidase subunit I (COI) sequence marker. However, only 10 individuals exhibiting haplotypic variation and a mere four haplotypes were detected in 560 O. robiniae samples. Thus, the genetic mechanisms behind successful invasion, the genetic structure in the process of colonization, and the phylogenetic relationships among the Chinese O. robiniae populations remain poorly understood.

Accordingly, to gain further insight into the genetic structure of the Chinese $O$. robiniae populations and ascertain how the species has spread widely in new regions, we used 11 microsatellite markers to analyze the genetic structure of 22 Chinese O. robiniae populations. Two native populations from the United States (US) were also assessed based on the same loci for comparison with the Chinese populations, in order to explain how genetic diversity is altered during the invasion process.

\section{MATERIALS AND METHODS}

\section{Sample Collection}

We collected the gall midge larvae and pupae contained within rolled leaves of host trees growing in 22 cities across China (Figure 1). Generally, the rolled leaves were randomly picked from different trees; however, when infestation was low, individual trees were singled out for sample collection. Following collection, the rolled leaves were immediately transported to the laboratory in $60 \mathrm{~cm} \times 40 \mathrm{~cm}$ plastic bags, in which they were maintained until adult emergence. From the samples collected at each location, 20 larger adults were selected, placed into a $1.5-\mathrm{mL}$ centrifuge tube, and stored at $-20^{\circ} \mathrm{C}$ for subsequent DNA extraction. Additionally, eight O. robiniae adults from two regions of the United States were obtained from the Quarantine Lab at the Institute of Forest Ecology, Environment, and Protection in the Chinese Academy of Forestry. Details of the sample collection and population codes are listed in Table $\mathbf{1 .}$

\section{DNA Extraction and Microsatellite Analyses}

Genomic DNA was extracted from the entire O. robiniae body following the instructions described by Zhou et al. (2007) and stored at $-20^{\circ} \mathrm{C}$ until needed. The 14 microsatellite loci (W3, W5, W8, W29, W31, W33, W35, W41, W46, W82, W83, W116, W126, and W132) developed by Yao et al. (2015) were initially selected to analyze the genotypes of 20 individuals per collection site (the exception being Zhengzhou, for which 16 individuals were analyzed) (Table 1). For each sample, we attempted to amplify all 14 loci; however, after two attempts, we were unable to amplify five loci (W29, W35, W41, W46, and W116) for many individuals; thus, these loci were not used in subsequent analyses. However, we assessed the applicability of two additional loci (W6 and W107; GenBank numbers: KP260520 and KP260530) that were not characterized by Yao et al. (2015), and we detected sufficient polymorphism among the analyzed samples. Hence, a total of 11 loci were used to genotype 444 O. robiniae individuals.

Microsatellite amplifications were performed in a $15 \mu \mathrm{L}$ reaction volume containing $1 \mu \mathrm{L}$ genomic DNA (10 ng), $1 \mu \mathrm{L}$ of each primer $(5 \mu \mathrm{mol} / \mathrm{L}), 7.5 \mu \mathrm{L} 2 \mathrm{X}$ Taq PCR Master Mix (TIANGEN, Beijing, China), and $4.5 \mu \mathrm{L} \mathrm{ddH}_{2} \mathrm{O}$. The forward primer of each primer pair was labeled with a fluorescent dye (HEX, ROX, FAM, or TMARA; Sangon Biotech, Shanghai, China). The microsatellite cycling protocol was: $5 \mathrm{~min}$ at $95^{\circ} \mathrm{C}$ 


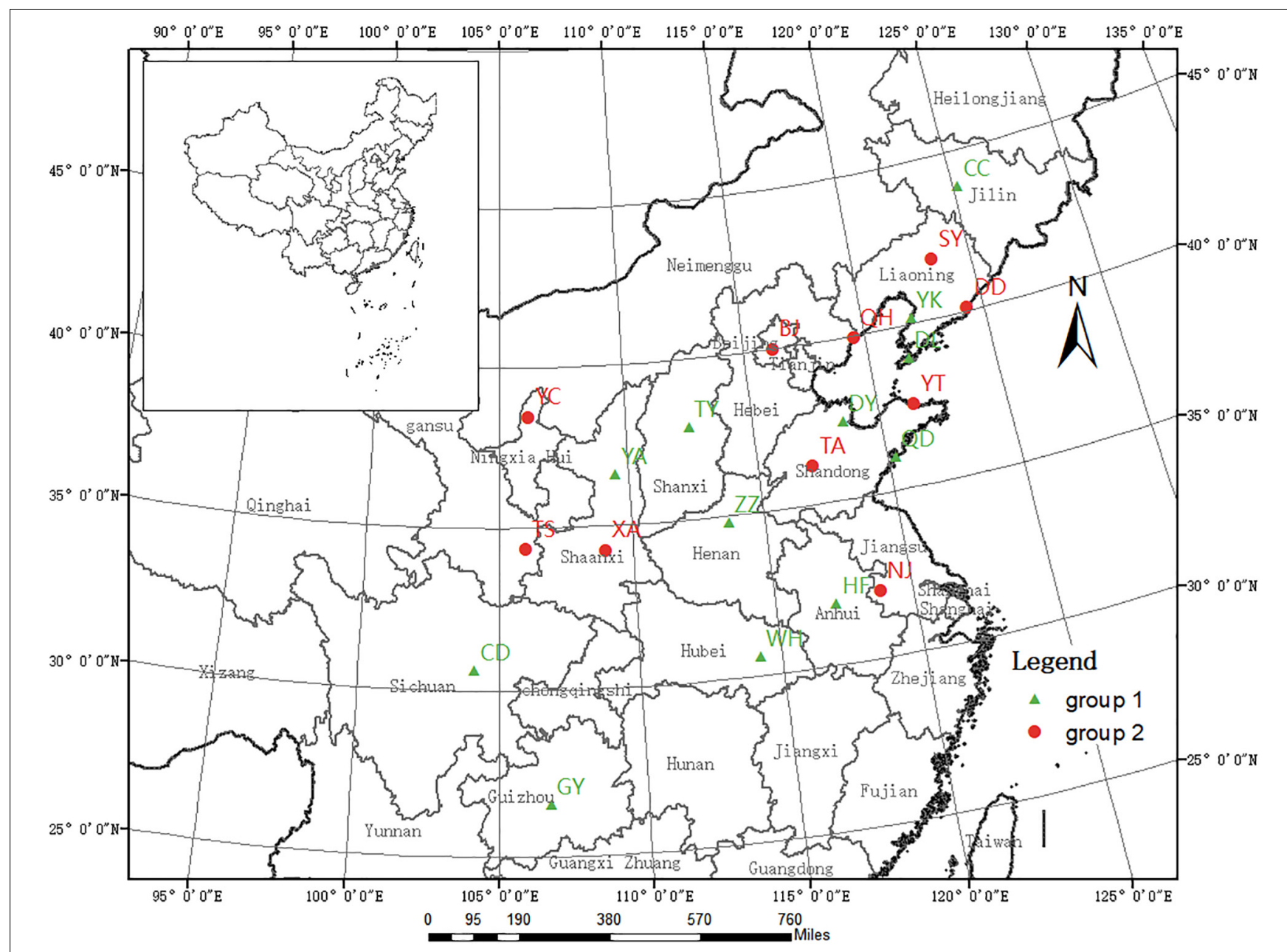

FIGURE 1 | Geographic locations of the 22 Chinese Obolodiplosis robiniae populations sampled. Population codes are listed in Table 1. (The source map was downloaded from the website http://www.webmap.cn/commres.do?method=dataDownload).

(initial denaturation step); followed by 30 cycles of $94^{\circ} \mathrm{C}$ for $30 \mathrm{~s}, 53^{\circ} \mathrm{C}\left(\mathrm{W} 3, \mathrm{~W} 5, \mathrm{~W} 6\right.$, and $\mathrm{W} 8$ ) or $56^{\circ} \mathrm{C}$ (the remaining loci) for $45 \mathrm{~s}, 72^{\circ} \mathrm{C}$ for $45 \mathrm{~s}$, extension at $72^{\circ} \mathrm{C}$ for $10 \mathrm{~min}$, and finally maintained at $16^{\circ} \mathrm{C}$. PCR products were examined using a DNA analyzer (Applied Biosystems, Waltham, CA, United States) and the results were analyzed using Genotyping was carried out using a 3730xl automated DNA sequencer (Applied Biosystems, Waltham, CA, United States). Alleles were scored using GeneMarker software version 2.2. (Softgenetics LLC, State College, PA, United States).

\section{Data Analyses}

Genetic diversity was estimated by basic statistical analyses including number of alleles $(\mathrm{Na})$, effective number of alleles $(\mathrm{Ne})$, Shannon's information index $(I)$, observed heterozygosity (Ho), expected heterozygosity $(\mathrm{He})$, and Nei's (1973) expected heterozygosity $(\mathrm{Nei})$, which were calculated using GenePop software version 4.3 (Rousset, 2008); genotype number (GN), gene diversity $(G D)$, and polymorphism information content (PIC) were calculated using PowerMarker software version V3.25
(Liu and Muse, 2005). F-statistics and gene flow for each locus across populations were performed using PopGene software version 1.32 (Yeh et al., 2018). Deviations from the HardyWeinberg equilibrium (HWE) based on the Markov chain algorithm (10,000 steps) and linkage disequilibrium (LD) (10,000 permutations) were also examined by GenePop software. The genetic relationships between populations were assessed using a neighbor-joining dendrogram generated by PowerMarker and Molecular Evolutionary Genetics Analysis across Computing Platforms (MEGA X) (Kumar et al., 2018).

Populations differentiation was assessed by pairwise Fst values (based on 999 permutations) and gene flow $(\mathrm{Nm})$ through AMOVA (analysis of molecular variance) approach which were performed using the Arlequin program version 3.5 (Excoffier and Lischer, 2010). The analyses can estimate variance and partitioning of the within- and among-population. Genetic structure analysis was performed with 100,000 Markov Chain Monte Carlo repetitions after a burn-in period of 200,000 interactions for each group number $(K)$ using STRUCTURE software version 2.3.4 (Pritchard et al., 2000). The number of 
TABLE 1 | Location of Obolodiplosis robiniae populations and the sample size used in this study.

\begin{tabular}{|c|c|c|c|c|c|c|}
\hline Number & Code & Site & Latitude (N) & Longitude (E) & Altitude & Sample size \\
\hline (1) & BJ & Beijing & $40^{\circ} 00.184^{\prime}$ & $116^{\circ} 14.363^{\prime}$ & 76 & 20 \\
\hline (2) & $\mathrm{CC}$ & Changchun, Jilin & $43^{\circ} 53.851^{\prime}$ & $125^{\circ} 16.329^{\prime}$ & 218 & 20 \\
\hline (3) & $\mathrm{CD}$ & Chengdu, Sichuan & $30^{\circ} 38.245^{\prime}$ & $104^{\circ} 07.334^{\prime}$ & 510 & 20 \\
\hline (4) & $\mathrm{DD}$ & Dandong, Liaoning & $40^{\circ} 06.906^{\prime}$ & $124^{\circ} 21.536^{\prime}$ & 33 & 20 \\
\hline (5) & $\mathrm{DL}$ & Dalian, Liaoning & $38^{\circ} 58.531^{\prime}$ & $121^{\circ} 36.800^{\prime}$ & 67 & 20 \\
\hline (6) & DY & Dongying, Shandong & $37^{\circ} 26.366^{\prime}$ & $118^{\circ} 34.448^{\prime}$ & 17 & 20 \\
\hline (7) & GY & Guiyang, Guizhou & $26^{\circ} 33.531^{\prime}$ & $106^{\circ} 45.003^{\prime}$ & 1090 & 20 \\
\hline (8) & $\mathrm{HF}$ & Hefei, Anhui & $31^{\circ} 52.824^{\prime}$ & $117^{\circ} 11.639^{\prime}$ & 39 & 20 \\
\hline (9) & $\mathrm{NJ}$ & Nanjing, Jiangsu & $32^{\circ} 03.426^{\prime}$ & $118^{\circ} 50.820^{\prime}$ & 90 & 20 \\
\hline (10) & QD & Qingdao, Shandong & $36^{\circ} 03.367^{\prime}$ & $120^{\circ} 20.934^{\prime}$ & 24 & 20 \\
\hline (11) & $\mathrm{QH}$ & Qinhuangdao, Hebei & $39^{\circ} 56.161^{\prime}$ & $119^{\circ} 35.411^{\prime}$ & 17 & 20 \\
\hline (12) & SY & Shenyang, Liaoning & $41^{\circ} 50.438^{\prime}$ & $123^{\circ} 25.690^{\prime}$ & 51 & 20 \\
\hline (13) & TA & Taian, Shandong & $36^{\circ} 12.225^{\prime}$ & $117^{\circ} 07.104^{\prime}$ & 208 & 20 \\
\hline (14) & TS & Tianshui, Gansu & $34^{\circ} 21.405^{\prime}$ & $106^{\circ} 00.034^{\prime}$ & 1460 & 20 \\
\hline$(15)$ & TY & Taiyuan, Shanxi & $37^{\circ} 54.592^{\prime}$ & $112^{\circ} 31.811^{\prime}$ & 798 & 20 \\
\hline (16) & $\mathrm{WH}$ & Wuhan, Hubei & $30^{\circ} 36.733^{\prime}$ & $114^{\circ} 17.772^{\prime}$ & 40 & 20 \\
\hline (17) & $X A$ & Xian, Shaanxi & $34^{\circ} 15.474^{\prime}$ & $108^{\circ} 58.938^{\prime}$ & 428 & 20 \\
\hline (18) & YA & Yanan, Shaanxi & $36^{\circ} 35.633^{\prime}$ & $109^{\circ} 29.535^{\prime}$ & 1121 & 20 \\
\hline (19) & YC & Yinchuan, Ningxia & $38^{\circ} 28.933^{\prime}$ & $106^{\circ} 11.983^{\prime}$ & 1115 & 20 \\
\hline (20) & YK & Yingkou, Liaoning & $40^{\circ} 12.432^{\prime}$ & $122^{\circ} 04.413^{\prime}$ & 15 & 20 \\
\hline (21) & YT & Yantai, Shandong & $37^{\circ} 32.024^{\prime}$ & $121^{\circ} 25.657^{\prime}$ & 9 & 20 \\
\hline$(22)$ & $\mathrm{ZZ}$ & Zhengzhou, Henan & $34^{\circ} 48.509^{\prime}$ & $113^{\circ} 42.266^{\prime}$ & 95 & 16 \\
\hline (23) & US_f & Finger Lakes, NY, United States & $42^{\circ} 45^{\prime}$ & $-76^{\circ} 41.4^{\prime} \mathrm{W}$ & - & 5 \\
\hline (24) & US_g & Goat Island, NY, United States & $43^{\circ} 48^{\prime}$ & $-79^{\circ} 42^{\prime} \mathrm{W}$ & - & 3 \\
\hline
\end{tabular}

subpopulations $(K)$ was assumed to be from 1 to 22 , without admixture and with correlated allele frequencies. To determine the most likely number of subpopulations, the optimum $K$-value was obtained by calculating the $\Delta K$ value (Evanno et al., 2005).

In addition, the Mantel test was conducted using the GenALEx 6.5 program (Peakall and Smouse, 2012) to determine correlations between Nei's genetic distance [was calculated using GenePop software based on Nei (1978)] and both geographical distance $(\mathrm{km})$ and altitude $(\mathrm{m})$. Significance was assessed by conducting 999 permutations. Moreover, a principal coordinate analysis (PCoA) was conducted using the same software.

\section{RESULTS}

\section{Microsatellite Polymorphism and Diversity}

In this study, locus polymorphism and diversity were determined based on 22 Chinese populations using 11 microsatellite markers, with each population consisting of 20 individual samples (except Zhengzhou, with 16 samples) (Table 1). Amplifying these microsatellite markers loci led to 436 polymorphic bands (Supplementary Table S1), representing 202 genotypes, ranging from 3 to 54 per primer pair. As shown in Table 2, there were 72 alleles among the 22 populations; the number of alleles $(\mathrm{Na})$ observed per locus varied from 2 (W83 and W107) to 14 (W3 and W5), with a mean of 6.5 per locus. The effective numbers of alleles $(\mathrm{Ne})$ varied from 1.4087 (W83) to 7.9971 (W3), with an average of 3.7255 per locus. The gene diversity index (GD) per locus ranged from 0.2901 (W83) to 0.8755 (W3), with an average of 0.6511 , indicating that a high level of information was provided by the 11 microsatellite markers. Shannon's information index (I) ranged from 0.4767 (W83) to 2.2573 (W3), with a mean of 1.3188 . The polymorphism information content (PIC) for the microsatellite loci ranged from 0.2494 (W83) to 0.8627 (W3), with an average of 0.6031 . The observed

TABLE 2 | Polymorphism of microsatellite loci across Chinese O. robiniae populations.

\begin{tabular}{lcccccccc}
\hline Locus & $\mathbf{N a}$ & $\mathbf{G N}$ & $\boldsymbol{N e}$ & $\mathbf{G D}$ & $\boldsymbol{I}$ & $\boldsymbol{H o}$ & $\boldsymbol{H e}$ & $\boldsymbol{P I C}$ \\
\hline W3 & 14 & 54 & 7.9971 & 0.8755 & 2.2573 & 0.7477 & 0.8760 & 0.8627 \\
W5 & 14 & 42 & 5.8768 & 0.8295 & 1.9743 & 0.7067 & 0.8308 & 0.8085 \\
W6 & 4 & 6 & 2.2687 & 0.5601 & 0.9575 & 0.3471 & 0.5599 & 0.4973 \\
W8 & 7 & 18 & 4.3609 & 0.7712 & 1.6184 & 0.3701 & 0.7716 & 0.7367 \\
W31 & 5 & 14 & 4.2747 & 0.7661 & 1.5224 & 0.6697 & 0.7669 & 0.7281 \\
W33 & 7 & 20 & 3.6391 & 0.7249 & 1.4660 & 0.6506 & 0.7260 & 0.6835 \\
W82 & 5 & 12 & 3.3448 & 0.7010 & 1.3193 & 0.3532 & 0.7018 & 0.6487 \\
W83 & 2 & 4 & 1.4087 & 0.2901 & 0.4767 & 0.3005 & 0.2905 & 0.2494 \\
W107 & 2 & 3 & 1.6205 & 0.3829 & 0.5710 & 0.2271 & 0.3833 & 0.3096 \\
W126 & 4 & 6 & 2.0018 & 0.5005 & 0.7223 & 0.4398 & 0.5010 & 0.3809 \\
W132 & 8 & 23 & 4.1874 & 0.7603 & 1.6214 & 0.4207 & 0.7621 & 0.7284 \\
Mean & 6.5 & 18.3636 & 3.7255 & 0.6511 & 1.3188 & 0.4757 & 0.6518 & 0.6031
\end{tabular}

Number of alleles (Na), genotype number (GN), effective number of alleles (Ne), gene diversity $(G D)$, Shannon's information index (I), observed heterozygosity (Ho), expected heterozygosity (He), polymorphism information content (PIC). 
heterozygosity $(\mathrm{Ho})$ ranged from 0.2271 (W107) to 0.7477 (W3) and expected heterozygosity $(\mathrm{He})$ ranged from 0.2905 (W83) to 0.8760 (W3). For each locus, both $\mathrm{Na}$ and $\mathrm{Ho}$ values markedly changed among populations, whereas, $\mathrm{He}$ value minorly altered (Supplementary Figure S1). In addition, when we evaluated the within-sample HWE deviations for each locus across all 22 Chinese populations using the Markov chain algorithm $(10,000$ steps), we detected significant deviation from the expected value $(p<0.05)$ in 68 of 242 tests $(28.10 \%)$ (Supplementary Table S2). Examination of genotypic LD between all pairs of alleles across all 22 populations, based on a permutation procedure $(10,000$ permutations), revealed a significant LD $(p<0.05)$ in 251 of 1210 tests $(20.74 \%)$ from 11 loci in the 22 Chinese populations.

\section{Population Genetic Diversity}

The genetic diversity of 22 Chinese populations and two US populations was assessed. Six indices of genetic diversity ( $\mathrm{Na}$, $\mathrm{Ne}, \mathrm{I}, \mathrm{Ho}, \mathrm{He}$, and $\mathrm{Nei}$ ) were evaluated. As shown in Table 3, for each Chinese population across all loci, the means of the above indices except $\mathrm{Na}$ were moderately or considerably lower than those of the native US populations, although the sample size of the Chinese populations (40) was markedly higher than that of the US populations (8). Regarding the three most important indices, $I, H e$, and $\mathrm{Nei}$, the lowest Chinese values $(I=0.7847$, $\mathrm{He}=0.4279, \mathrm{Nei}=0.4172)$ occurred in the DY population, and the highest $(I=1.1103, \mathrm{He}=0.6162, \mathrm{Nei}=0.6008)$ in the TS population. Increased values of these three indices occurred in the SY $(I=1.058, \mathrm{He}=0.6157, \mathrm{Nei}=0.6003)$, YT $(I=1.0761$, $\mathrm{He}=0.5825, \mathrm{Nei}=0.5677)$, and DD $(I=1.016, \mathrm{He}=0.5895$, $\mathrm{Nei}=0.5748$ ) populations. The inbreeding coefficient $($ Fis) ranged from -0.0295 (TY) to 0.2011 (CD), with significant various observed for each locus among populations. Both US populations exhibited high $\mathrm{He}$ values of 0.6544 (US_f) and 0.6606 (US_g).

\section{Genetic Differentiation in the Chinese Populations}

The Fst per locus ranged from 0.1357 to 0.3770 , with an average of 0.1994, and the Fis per locus ranged from -0.0037 (W3) to 0.3364 (W82) with an average of 0.0873 alleles per locus across populations (Table 4). Gene flow $(\mathrm{Nm})$ ranged from 0.3093 at W31 to 1.5921 at W33 and averaged 1.0036. Meanwhile, the pairwise Fst $(p<0.001)$ values (Supplementary Table S3) between populations ranged from 0.022 ( $\mathrm{HF}$ and $\mathrm{WH}$ ) to 0.377 (BJ and GY), with an average value of 0.183 . A total of 135 of the 213 Fst values (63.38\%) were $>0.15$, while $48(22.54 \%)$ were $>0.25$, which suggests that significant genetic differentiation

TABLE 3 | Genetic diversity of the O. robiniae populations across 11 microsatellite loci.

\begin{tabular}{|c|c|c|c|c|c|c|c|c|}
\hline Code & Sample size & $\mathrm{Na}$ & $\mathrm{Ne}$ & $I$ & Ho & $\mathrm{He}$ & Nei & Fis \\
\hline BJ & 40 & 3.3636 & 2.375 & 0.868 & 0.4591 & 0.4928 & 0.4805 & 0.0445 \\
\hline CC & 40 & 3.7273 & 2.5568 & 0.9673 & 0.4364 & 0.5425 & 0.529 & 0.1751 \\
\hline$C D$ & 40 & 3.4545 & 2.1684 & 0.8976 & 0.4136 & 0.531 & 0.5177 & 0.2011 \\
\hline DD & 40 & 3.5455 & 2.651 & 1.016 & 0.5591 & 0.5895 & 0.5748 & 0.0273 \\
\hline $\mathrm{DL}$ & 40 & 3.1818 & 2.3375 & 0.8675 & 0.5636 & 0.5026 & 0.49 & -0.1503 \\
\hline DY & 40 & 3.2727 & 2.2412 & 0.7847 & 0.4409 & 0.4279 & 0.4172 & -0.0569 \\
\hline GY & 40 & 3.5455 & 2.0894 & 0.8164 & 0.3864 & 0.4705 & 0.4588 & 0.1578 \\
\hline $\mathrm{HF}$ & 40 & 3.1818 & 2.5997 & 0.9554 & 0.4909 & 0.5742 & 0.5599 & 0.1232 \\
\hline NJ & 40 & 3.8182 & 2.4202 & 0.9633 & 0.4364 & 0.5408 & 0.5273 & 0.1724 \\
\hline QD & 40 & 3.3636 & 2.2096 & 0.8265 & 0.3682 & 0.4647 & 0.4531 & 0.1874 \\
\hline $\mathrm{QH}$ & 40 & 3.6364 & 2.2661 & 0.9192 & 0.5318 & 0.5233 & 0.5102 & -0.0423 \\
\hline SY & 40 & 3.7273 & 2.797 & 1.058 & 0.5455 & 0.6157 & 0.6003 & 0.0914 \\
\hline TA & 40 & 3.3636 & 2.0576 & 0.8347 & 0.439 & 0.4792 & 0.4672 & 0.0603 \\
\hline TS & 40 & 4.0909 & 2.8428 & 1.1103 & 0.5045 & 0.6162 & 0.6008 & 0.1602 \\
\hline TY & 40 & 3.6364 & 2.3278 & 0.9101 & 0.5273 & 0.5253 & 0.5122 & -0.0295 \\
\hline WH & 40 & 3.7273 & 2.5723 & 0.9797 & 0.5256 & 0.5599 & 0.5459 & 0.0371 \\
\hline XA & 40 & 3.5455 & 2.535 & 0.9503 & 0.5182 & 0.5492 & 0.5355 & 0.0323 \\
\hline YA & 40 & 3.8182 & 2.7608 & 0.9798 & 0.4199 & 0.5355 & 0.5221 & 0.1958 \\
\hline YC & 40 & 3.8182 & 2.4284 & 0.9586 & 0.467 & 0.5369 & 0.5234 & 0.1078 \\
\hline YK & 40 & 4.4545 & 2.6524 & 1.0623 & 0.4682 & 0.567 & 0.5528 & 0.1531 \\
\hline YT & 40 & 4.2727 & 2.9205 & 1.0761 & 0.5081 & 0.5825 & 0.5677 & 0.1049 \\
\hline $\mathrm{ZZ}$ & 30 & 3.4545 & 2.3364 & 0.912 & 0.4516 & 0.5346 & 0.5168 & 0.1261 \\
\hline CN mean & 40 & 3.6363 & 2.4612 & 0.9415 & 0.4755 & 0.5346 & 0.5192 & - \\
\hline US_f & 10 & 4.0909 & 3.2336 & 1.1472 & 0.5 & 0.6544 & 0.5875 & 0.1489 \\
\hline US_g & 6 & 3.0909 & 2.6363 & 0.9632 & 0.5152 & 0.6606 & 0.5505 & 0.0642 \\
\hline US mean & 8 & 3.5909 & 2.935 & 1.0552 & 0.5076 & 0.6575 & 0.569 & - \\
\hline
\end{tabular}

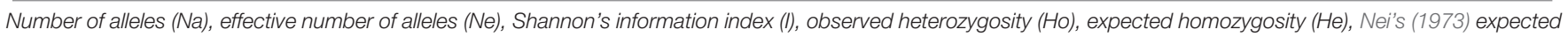
heterozygosity (Nei), inbreeding coefficient (Fis). 
TABLE 4 | Summary of $F$ statistics and gene flow for each locus.

\begin{tabular}{lrcc}
\hline Locus & Fis & Fst & Nm \\
\hline W3 & -0.0037 & 0.1487 & 1.4307 \\
W5 & 0.0026 & 0.1460 & 1.4629 \\
W6 & 0.0040 & 0.3770 & 0.4130 \\
W8 & 0.2929 & 0.3198 & 0.5317 \\
W31 & -0.0441 & 0.1603 & 1.3093 \\
W33 & -0.0364 & 0.1357 & 1.5921 \\
W82 & 0.3364 & 0.2379 & 0.8007 \\
W83 & -0.1980 & 0.1367 & 1.5792 \\
W107 & 0.3182 & 0.1402 & 1.5337 \\
W126 & -0.0165 & 0.1379 & 1.5634 \\
W132 & 0.2870 & 0.2230 & 0.8745 \\
Mean & 0.0873 & 0.1994 & 1.0036 \\
\hline
\end{tabular}

Gene flow (Nm) estimated based on Nm =0.25(1- Fst)/Fst.

TABLE 5 | Population genetic variance revealed by 11 microsatellite loci through AMOVA analysis.

\begin{tabular}{lccccc}
\hline Source & $\begin{array}{c}\text { Segree of } \\
\text { freedom }\end{array}$ & $\begin{array}{c}\text { Sum of } \\
\text { squared } \\
\text { deviations }\end{array}$ & $\begin{array}{c}\text { Mean } \\
\text { squared } \\
\text { deviations }\end{array}$ & $\begin{array}{c}\text { Variance } \\
\text { component }\end{array}$ & $\begin{array}{c}\text { Percentage } \\
\text { estimates }\end{array}$ \\
of variation
\end{tabular}

exists among the sampling sites and there is some restriction in gene flow between them (Table 4). The most noticeable genetic differentiation occurred between BJ and GY $(F s t=0.377)$, followed by GY and QH $(F s t=0.372)$, then DY and QH, DY and GY (Fst $=0.361$ for both). According to the coefficient of genetic differentiation $(F s t=0.1830, p<0.001)$, genetic variation within populations $(81.66 \%)$ was substantially higher than that among populations $(18.34 \%)(p<0.001)$ (Table 5). Gene flow $(\mathrm{Nm})$ ranged from $0.414(\mathrm{BJ}$ and $\mathrm{GY})$ to $11.05(\mathrm{HF}$ and $\mathrm{WH})$ (Supplementary Table S4), with an average of 1.113 (Table 5). All investigated loci contributed to the population differentiation ( $p<0.001$ for each individual locus). Regarding the native US populations, they had a relatively low Fst value $(0.085, p<0.03)$, a high $N m$ value (2.685), and variation within populations of $91 \%$, while variation among populations was $9 \%(p<0.02)$. This further indicates the existence of extensive genetic differentiation among the introduced populations.

\section{Genetic Relationships and Population Structure Analysis}

A dendrogram depicting the genetic relationships among the 22 Chinese populations was constructed based on the microsatellite data (Figure 2). The populations were divided into two main clusters, and each cluster was further separated into several sub-clusters. Group I contained populations from Northeast China (Jilin Province) to Southwest China (Guizhou Province), including Liaoning (YK, DL), Jilin (CC), Shanxi (TY), Shaanxi (YA), Shandong (DY, QD), Henan (ZZ), Sichuan (CD), Hubei (WH), Anhui (HF), and Guizhou (GY) provinces. Group II contained populations from North China (with the exception of the NJ population), including Beijing (BJ), Liaoning (SY, DD), Hebei (QH), Shandong (YT, TA), Shaanxi (XA), Gansu (TS), Ningxia (YC), and Jiangsu (NJ) provinces. Besides, some subdivided populations were clustered according to their spatial distribution, such as GY, HF, and WH located in the south of southern China, which clustered together in group I, whereas $\mathrm{TA}, \mathrm{DD}, \mathrm{BJ}$, and $\mathrm{QH}$ located around Bohai Bay clustered together in group II.

The 436 Chinese O. robiniae samples were further assessed for population stratification using STRUCTURE software. Microsatellite data were analyzed with possible cluster numbers ( $K$-values) ranging from 1 to $22 . \Delta K$ was clearly maximized when $K=2(\Delta K=4298.3743)$, indicating the occurrence of two distinct groups among the 22 populations (Figure 3), which validates the dendrogram-based grouping, and the second clade was grouped according to approximate geographical area. These results suggested different degrees of introgression in the populations, detected as differences in allelic frequencies among the populations. In addition, greater structuring $(K=3)$ revealed that QD, GY, and TY in group I had certain structural similarities to YT, SY, NJ, YC, and XA in group II.

In addition, PCoA based on the marker genotypes also revealed two distinct clusters of the Chinese populations (Figure 4), which were partly related to their geographical regions (group II contained populations from North China). The Mantel test revealed non-significant negative correlations between Nei's genetic distance (Supplementary Table S5) and geographical distance $(\mathrm{km})(r=-0.02, P=0.456$; Supplementary Figure S2), and between Nei's genetic distance and altitude $(r=-0.026$, $P=0.419$; Supplementary Figure S3), which indicates that genetic differentiation in the 22 Chinese populations may not be caused by geographical isolation.

\section{DISCUSSION}

In the present study, we detected a high degree of polymorphism among the assessed microsatellite loci. We also identified a relatively high level of genetic diversity among Chinese O. robiniae populations across all loci, with the average expected heterozygosity (He) and Nei's (1973) expected heterozygosity (Nei) being 0.5346 and 0.5192 , respectively. The highest $\mathrm{He}$ was 0.6606 , which occurred in the US_g population despite the fact that it consisted of only three $O$. robiniae individuals. Nonetheless, He, Nei (Shang et al., 2016), gene diversity index 


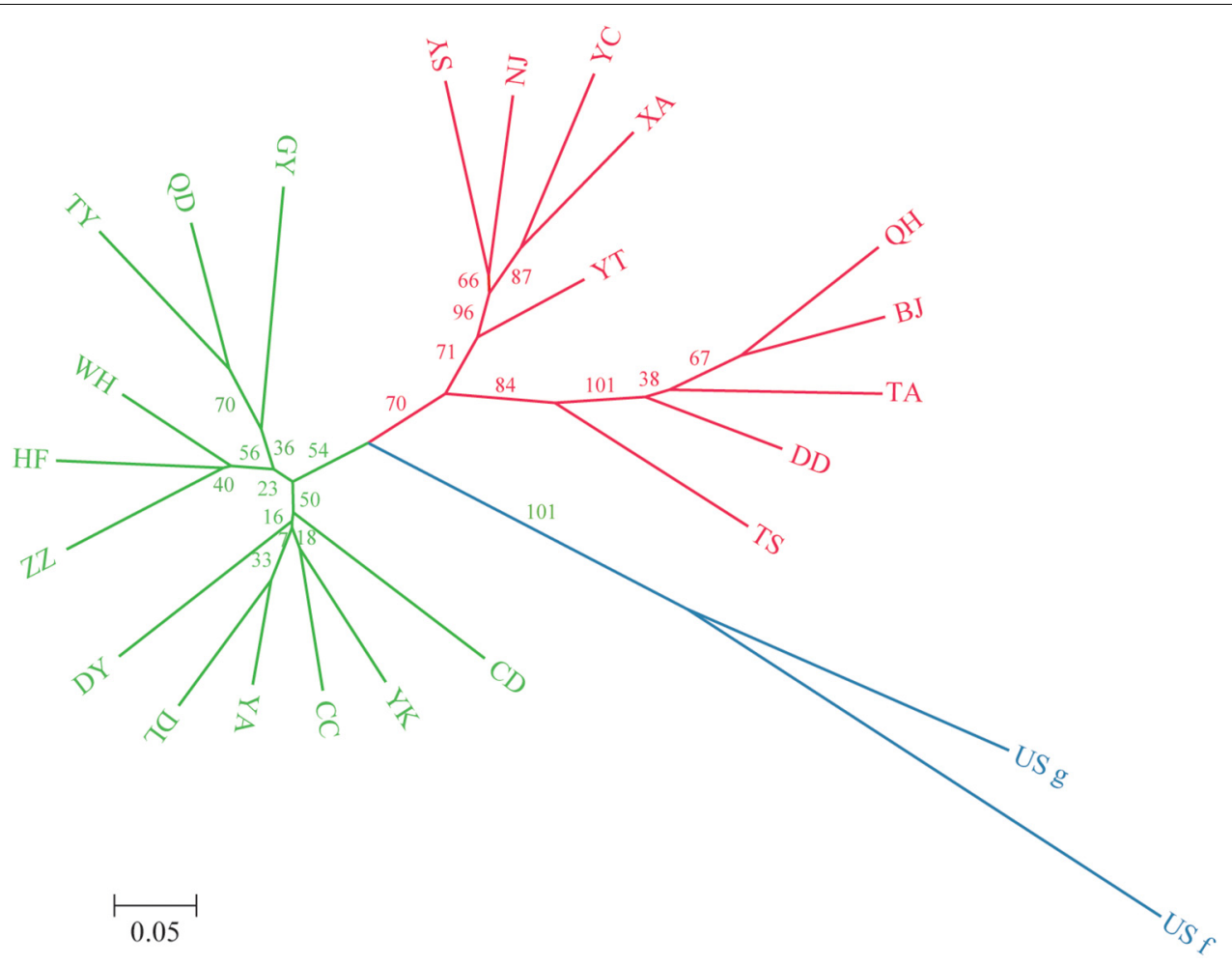

FIGURE 2 | Unrooted neighbor-joining dendrogram of the 24 O. robiniae populations based on Nei's distance using the allele frequencies of 11 microsatellite loci. Green represents the subpopulations of group 1, red represents the subpopulations of group 2, and blue represents the US populations.

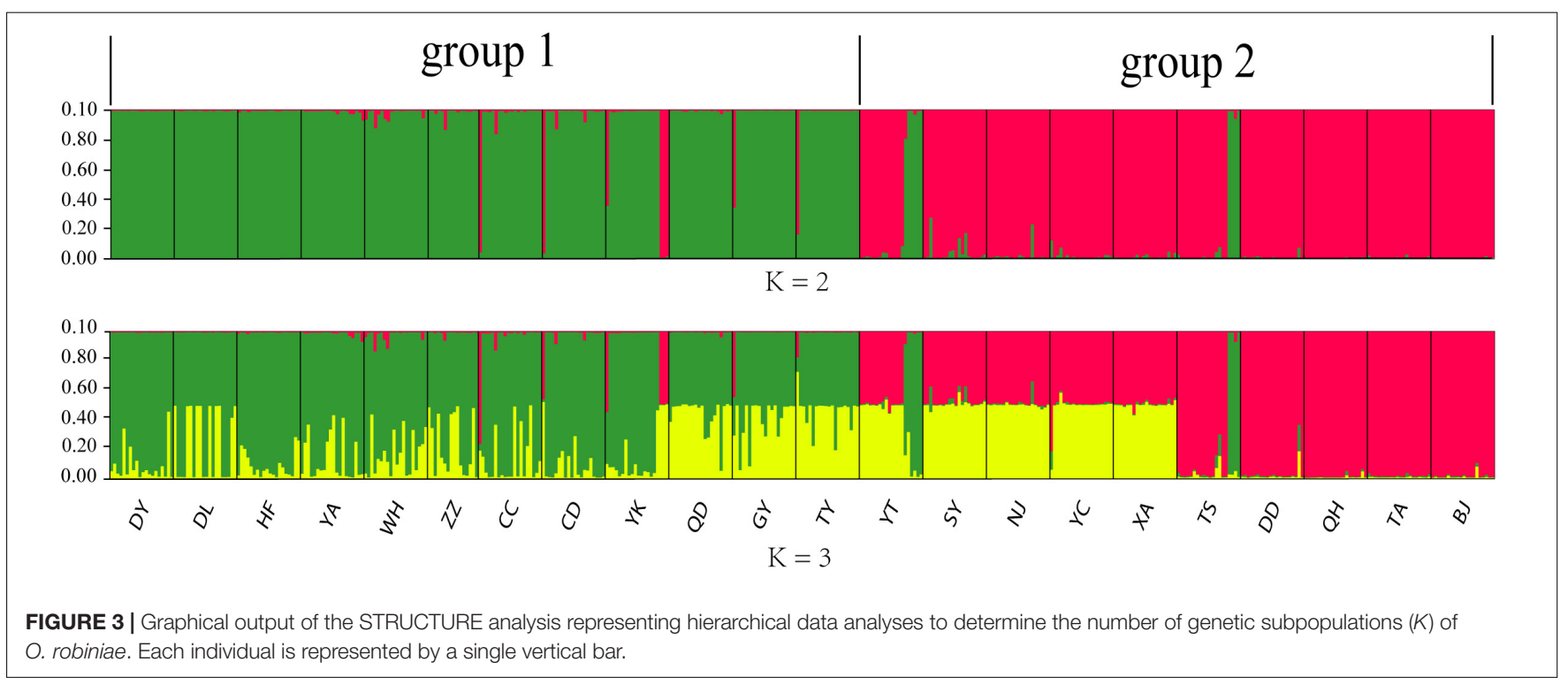

(GD), and polymorphism information content (PIC) (Ren et al., 2014) are minimally influenced by sample size. Our results indicate significant differences in genetic diversity within the Chinese populations, as well as between the native and invasive populations. Shang et al. (2015b) detected a relatively low level of genetic diversity among Chinese O. robiniae populations using a COI marker. This discrepancy suggests that COI markers may be less suitable than microsatellite DNA markers for population analyses of a new invasive species, such as Chinese O. robiniae, as is the case with another invasive cecidomyiid, Procontarinia mangiferae (Amouroux et al., 2013).

The relatively high level of genetic diversity has likely contributed to the spread of O. robiniae across China in the past decade to the extent that this species is now established in most 


\section{Principal Coordinates (PCoA)}

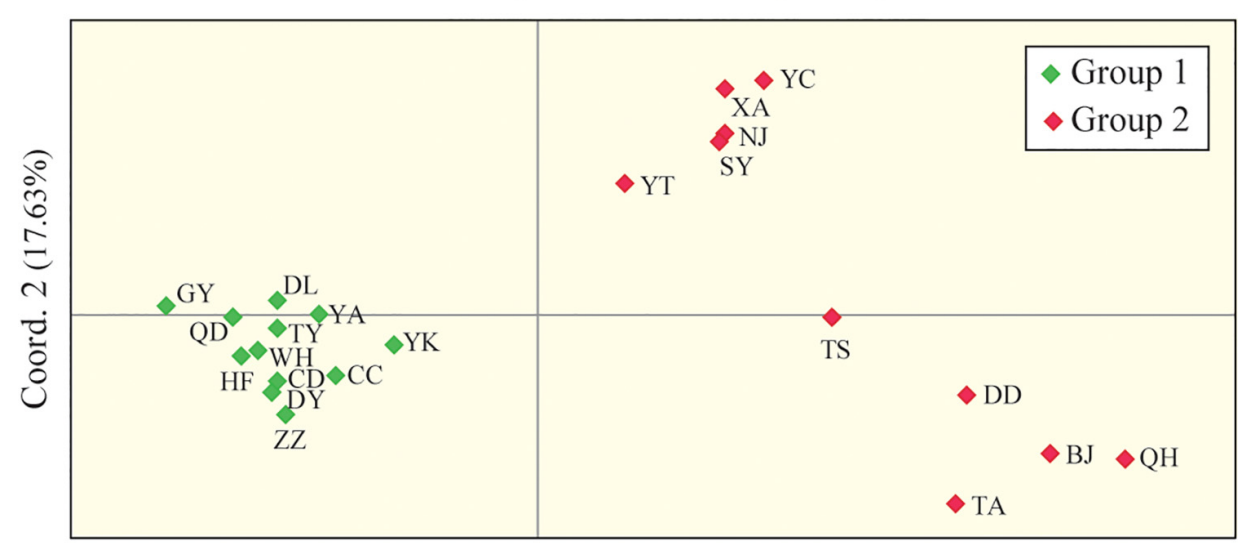

Coord. 1(39.51\%)

FIGURE 4 | Principal coordinate analysis (PCOA) of 436 Chinese O. robiniae individuals showing two distinct clusters of populations. Each population is represented by a diamond. Coord.1 (39.51\%) and Coord.2 (17.63\%) refer to the first and second principal component, respectively.

regions where its host exists (Shang et al., 2015a). O. robiniae has a short history in China, with initial detection occurring in 2004 (Yang et al., 2006), whereas its host was introduced over a century ago (Xu and Yang, 2006). Moreover, for the 22 Chinese populations analyzed, our results show a relatively high level of genetic differentiation $(F s t=0.1830)$ among populations from sites separated by distances of up to $2,540 \mathrm{~km}$. Hence, the relatively high genetic diversity likely caused by significant differentiation among populations has been conducive to the rapid colonization and establishment of $O$. robiniae in China, and it is an important factor contributing to the successful invasion of $O$. robiniae.

The observed population differentiation likely resulted from rapid evolution during adaptation to the new environment. Invasive species may evolve rapidly in response to selection pressures driven by novel habitats (Sakai et al., 2001; Lee, 2002; Ochocki and Miller, 2017), and such rapid genetic adaptation might be important for invasive species (Shine et al., 2011) in order to increase fitness and invasion success (Suarez and Tsutsui, 2008; Roux and Wieczorek, 2009). Increasing the success of both their initial establishment and subsequent range expansion is a particularly effective strategy for introduced populations, as was shown for several invasive species during their colonization processes (Simberloff et al., 2013; Ochocki and Miller, 2017; Wu et al., 2019). Hence, differentiation among Chinese populations was likely accelerated by the rapid evolution of adaptations to the new environments, promoting successful invasion by $O$. robiniae.

Furthermore, high levels of genetic diversity in an invasive species might be caused by multiple introductions or large founding populations. It is thought that multiple introductions are associated with increased diversity because they supply increased variation and new genetic communities (Dlugosch and Parker, 2008). Multiple introductions are considered to produce invasive populations that are much more genetically diverse than a single source population (Sakai et al., 2001). As such, the successful establishment and invasion of many invasive species have been attributed to multiple introductions (Meixner et al., 2002; Kolbe et al., 2004; Cheng et al., 2008; Zalewski et al., 2010; Michaelides et al., 2018). For O. robiniae, in light of the short history in China, its high genetic diversity and colonization success might be also related to multiple independent invasive events.

Many studies have shown that the genetic structures of invasive species are well developed in their new ranges (Zeisset and Beebee, 2003; Herborg et al., 2007; Rollins et al., 2009; Zalewski et al., 2010). Indeed, the genetic diversity of invasive species is often higher than that of native populations (Marrs et al., 2008). In light of this, our neighbor-joining dendrogram and Bayesian STRUCTURE $(K=2)$ analyses indicated that the Chinese $O$. robiniae populations are divided into two independent clusters, although this division appears to be unrelated to geographical distribution. Meanwhile, gene flow was found among some Chinese populations, with QD, GY, and TY in group I having highly similar structures to YT, SY, NJ, YC, and XA in group II. In addition, some subgroups (GY, HF, and $\mathrm{WH}$; TA, DD, BJ, and $\mathrm{QH}$ ) were clustered according to their geographical distribution, which likely represents different routes of spread in the new environment. Furthermore, our results revealed that each group of the Chinese $O$. robiniae populations exhibited differences in geographical distribution and genetic distance, suggesting that the two groups do in fact represent two different sources. This implies the introduced populations likely experienced two independent invasive events, which initially shaped the genetic structure of the Chinese $O$. robiniae populations.

On the other hand, the fact that the division of the two groups was unrelated to geographical distribution (particularly for group I, which contained numerous genetically similar populations located in different geographical regions) suggests that human activity is likely another important contributing factor. Transport, business trips, and long-distance vacations have recently increased not only in frequency but also in distance. High levels of human-mediated dispersion can increase the 
genetic diversity of an invasive population, thereby substantially modifying the genetic structure and potential management units (Perkins et al., 2013); these factors decrease the success of control measures for O. robiniae populations.

\section{DATA AVAILABILITY STATEMENT}

All datasets generated for this study are included in the article/Supplementary Material.

\section{AUTHOR CONTRIBUTIONS}

Y-XY and W-XZ: conceptualization, funding acquisition, project administration, and supervision. R-ZL, W-XH, and JY: data curation. Y-XY, X-PS, and JY: formal analysis, investigation, and resources. Y-XY and X-PS: methodology. Y-XY and R-ZL: software. Y-XY, R-ZL, and W-XH: validation. Y-XY, X-PS, R-ZL, and $\mathrm{W}-\mathrm{XH}$ : visualization. Y-XY, X-PS, R-ZL, W-XH, JY, and $\mathrm{W}-\mathrm{XZ}$ : writing - original draft and review and editing.

\section{REFERENCES}

Amouroux, P., Normand, F., Nibouche, S., and Delatte, H. (2013). Invasive mango blossom gall midge, Procontarinia mangiferae (Felt) (Diptera: Cecidomyiidae) in Reunion Island: ecological plasticity, permanent and structured populations. Biol. Invasions 15, 1677-1693. doi: 10.1017/S0007485314000480

Anjos, L. O., Peixoto, R. F. Jr., Chanquinie, D. M., Pinto, L. R., Creste, S. A., Dinardo-Miranda, L. L., et al. (2016). Microsatellite loci and genetic structure of artificial populations of Cotesia flavipes (Hymenoptera, Braconidae). Genet. Mol. Res. 15:gmr.15048851. doi: 10.4238/gmr15048851

Badmin, J. (2016). Obolodiplosis robiniae (Haldeman) (Diptera: Cecidomyiidae) on False-acacia cv Frisia. Br. J. Entomol. Nat. Hist. 29:245.

Bentur, J. S., Sinha, D. K., Padmavathy, R. C., Muthulakshmi, M., and Nagaraju, J. (2011). Isolation and characterization of microsatellite loci in the Asian rice gall midge (Orseolia oryzae) (Diptera: Cecidomyiidae). Int. J. Mol. Sci. 12, 755-772. doi: 10.3390/ijms12010755

Bonizzoni, M., Malacrida, A. R., Guglielmino, C. R., Gomulski, L. M., Gasperi, G., and Zheng, L. (2000). Microsatellite polymorphism in the Mediterranean fruit fly, Ceratitis capitata. Insect Mol. Biol. 9, 251-261. doi: 10.1046/j.1365-2583. 2000.00184.x

CABI/EPPO (2011). Obolodiplosis robiniae. Distribution Maps of Plant Pests. Wallingford: $C A B I$.

Cheng, X. Y., Cheng, F. X., Xu, R. M., and Xie, B. Y. (2008). Genetic variation in the invasive process of Bursaphelenchus xylophilus (Aphelenchida: Aphelenchoididae) and its possible spread routes in China. Heredity 100, 356-365. doi: 10.1038/sj.hdy.6801082

Cierjacks, A., Kowarik, I., Joshi, J., Hempel, S., Ristow, M., Lippe, M., et al. (2013). Biological flora of the British Isles: Robinia pseudoacacia. J. Ecol. 101, 1623-1640.

Davis, M. A. (2009). Invasion Biology. New York, NY: Oxford University Press.

Dlugosch, K. M., and Parker, I. M. (2008). Founding events in species invasions: genetic variation, adaptive evolution, and the role of multiple introductions. Mol. Ecol. 17, 431-449. doi: 10.1111/j.1365-294x.2007.03538.x

Duan, X., Wang, K., Su, S., Tian, R., Li, Y., and Chen, M. (2017). De novo transcriptome analysis and microsatellite marker development for population genetic study of a serious insect pest, Rhopalosiphum padi (L.) (Hemiptera: Aphididae). PLoS One 12:e0172513. doi: 10.1371/journal.pone.017 2513

Duso, C., Fontana, P., and Tirello, P. (2005). Spread of the gall midge Obolodiplosis robiniae (Haldeman) injurious to black locust in Italy and Europe. Inform. Fitopatol. 55, 30-33.

\section{FUNDING}

This work was funded by the Fundamental Research Funds of the Chinese Academy of Forestry (CAFYBB2017SZ003) and the National Key R\&D Program of China (2016YFC1201200).

\section{ACKNOWLEDGMENTS}

We would like to thank Dr. Yan-Fei Zeng (Research Institute, Chinese Academy of Forestry) for discussions regarding the data. We also sincerely thank the other members of the Plant Quarantine Lab and Plant Pathology Lab of the Chinese Academy of Forestry for their helpful comments.

\section{SUPPLEMENTARY MATERIAL}

The Supplementary Material for this article can be found online at: https://www.frontiersin.org/articles/10.3389/fgene. 2020.00387/full\#supplementary-material

Evanno, G., Regnaut, S., and Goudet, J. (2005). Detecting the number of clusters of individuals using the software STRUCTURE: a simulation study. Mol. Ecol. 14, 2611-2620. doi: 10.1111/j.1365-294x.2005.02553.x

Excoffier, L., and Lischer, H. E. L. (2010). Arlequin suite version 3.5: a new series of programs to perform population genetics analyses under Linux and Windows. Mol. Ecol. Res. 10, 564-567. doi: 10.1111/j.1755-0998.2010.02847.x

Facon, B., Genton, B. J., Shykoff, J., Jarne, P., Estoup, A., and David, P. A. (2006). General eco-evolutionary framework for understanding bioinvasions. Trends Ecol. Evol. 21, 130-135. doi: 10.1016/j.tree.2005.10.012

Haldeman, S. S. (1847). Description of several new and interesting animals. Am. J. Agr. Sci. 6, 191-194.

Herborg, L. M., Weetman, D., Van Oosterhout, C., and Hanfling, B. (2007). Genetic population structure and contemporary dispersal patterns of a recent European invader, the Chinese mitten crab, Eriocheir sinensis. Mol. Ecol. 16, 231-242. doi: 10.1111/j.1365-294x.2006.03133.x

Horst, C. P., and Lau, J. A. (2015). Genetic variation in invasive species response to direct and indirect species interactions. Biol. Invasions 17, 651-659. doi: 10.1111/j.1469-185X.2010.00123.x

Kim, S. R., Kim, K. Y., Jeong, J. S., Kim, M. J., Kim, K. H., Choi, K. H., et al. (2017). Population genetic characterization of the Japanese oak silkmoth, Antheraea yamamai (Lepidoptera: Saturniidae), using novel microsatellite markers and mitochondrial DNA gene sequences. Genet. Mol. Res. 16:gmr16029608. doi: 10.4238/gmr16029608

Kolbe, J. J., Glor, R. E., Schettino, L. R. G., Lara, A. C., Larson, A., and Losos, J. B. (2004). Genetic variation increases during biological invasion by a Cuban lizard. Nature 431, 177-181. doi: 10.1038/nature02807

Kong, L., Bai, J., and Li, Q. (2014). Comparative assessment of genomic SSR, EST-SSR and EST-SNP markers for evaluation of the genetic diversity of wild and cultured Pacific oyster, Crassostrea gigas Thunberg. Aquaculture 420-42, S85-S91.

Kostro-Ambroziak, A., and Mieczkowska, A. (2017). The first record of the black locust gall midge Obolodiplosis robiniae (Haldeman, 1847) (Diptera: Cecidomyiidae) from northeastern Poland. Wiadomosci Entomol. 36:755.

Kumar, S., Stecher, G., Li, M., Knyaz, C., and Tamura, K. (2018). MEGA X: molecular evolutionary genetics analysis across computing platforms. Mol. Biol. Evol. 35, 1547-1549. doi: 10.1093/molbev/msy096

Launey, S., Brunet, G., Guyomard, R., and Davaine, P. (2010). Role of introduction history and landscape in the range expansion of brown trout (Salmo trutta L.) in the Kerguelen Islands. J. Hered. 10, 270-283. doi: 10.1093/jhered/esp130

Lee, C. E. (2002). Evolutionary genetics of invasive species. Trends Ecol. Evol. 17, 386-391. doi: 10.1016/s0169-5347(02)02554-5 
Lee, J. S., Jung, Y. M., Choi, K. S., Kim, I. K., Kwon, Y. D., Jeon, M. J., et al. (2009). Seasonal fluctuation and distribution of Obolodiplosis robiniae (Diptera: Cecidomyiidae) within crown of Robinia pseudoacacia (Fabaceae). Korean J. App. Entomol. 48, 447-451. doi: 10.5656/ksae.2009.48.4.447

Liu, K., and Muse, S. V. (2005). Powermarker: integrated analysis environment for genetic marker data. BMC Bioinformatics 21:2128-2129. doi: 10.1093/ bioinformatics/bti282

Liu, Y. B. (2014). Management methods to control Obolodiplosis robiniae. Gansu Agric. 2, 87-88.

Marrs, R. A., Sforza, R., and Hufbauer, R. A. (2008). When invasion increases population genetic structure: a study with Centaurea diffusa. Biol. Invasions 10, 561-572. doi: 10.1007/s10530-007-9153-6

Meixner, M. D., Mcpheron, B. A., Silva, J. G., Gasparich, G. E., and Sheppard, W. S. (2002). The Mediterranean fruit fly in California: evidence for multiple introductions and persistent populations based on microsatellite and mitochondrial DNA variability. Mol. Ecol. Notes 11, 891-899. doi: 10.1046/j. 1365-294x.2002.01488.x

Mezghani-Khemakhem, M., Bouktila, D., Casse, N., Maaroufi, H., Makni, M., and Makni, H. (2012). Development of new polymorphic microsatellite loci for the barley stem gall midge, Mayetiola hordei (Diptera: Cecidomyiidae) from an enriched library. Int. J. Mol. Sci. 13, 14446-14450. doi: 10.3390/ijms13111 4446

Michaelides, S. N., Goodman, R. M., Crombie, R. I., Kolbe, J. J., and Cowie, R. (2018). Independent introductions and sequential founder events shape genetic differentiation and diversity of the invasive green anole (Aanolis carolinensis) on pacific islands. Divers. Distrib. 24, 666-679. doi: 10.1111/ddi.12704

Mihajlovic, L., Glavendekic, M. M., Jakovljevic, I., and Marjanovic, S. (2008). Obolodiplosis robiniae (Haldeman) (Diptera: Cecidomyiidae) - a new invasive insect pest on black locust in Serbia. Glas. Sumarskog Fakult. Univ. Beogr. 97, 197-207. doi: 10.2298/gsf0897197m

Mu, X. F., Sun, J. S., Lu, W. F., Li, M., Qu, H. X., and Gao, Z. Y. (2010). Bionomics and control of Obolodiplosis robiniae in Beijing. For. Pest Dis. 29, 15-18.

Nei, M. (1973). Analysis of gene diversity in subdivided populations. Proc. Natl. Acad. Sci. 70, 3321-3323. doi: 10.1073/pnas.70.12.3321

Nei, M. (1978). Estimation of average heterozygosity and genetic distance from a Small Number of Individuals. Genetics 89, 583-590.

Nei, M., Maruyama, T., and Chakraborty, R. (1975). The bottleneck effect and genetic variability in populations. Evolution 29, 1-10. doi: 10.1111/j.1558-5646. 1975.tb00807.x

Ochocki, B. M., and Miller, T. E. X. (2017). Rapid evolution of dispersal ability makes biological invasions faster and more variable. Nat. Commun. 8:14315. doi: $10.1038 /$ ncomms 14315

Peakall, R., and Smouse, P. E. (2012). GenAlEx 6.5: genetic analyses in Excel. Population genetic software for teaching and research-an update. BMC Bioinformatics 28, 2537-2539. doi: 10.1093/bioinformatics/bts460

Perkins, T. A., Phillips, B. L., Baskett, M. L., and Hastings, A. (2013). Evolution of dispersal and life history interact to drive accelerating spread of an invasive species. Ecol. Lett. 16, 1079-1087. doi: 10.1111/ele.12136

Pritchard, J. K., Stephens, M., and Donnelly, P. (2000). Inference of population structure using multilocus genotype data. Genetics 155, 945-959.

Ren, X. P., Jiang, H. F., Yan, Z. Y., Chen, Y., Zhou, X. J., Huang, L., et al. (2014). Genetic diversity and population structure of the major peanut (Arachis hypogaea L.) cultivars grown in China by SSR markers. PLoS One 9:e88091. doi: 10.1371/journal.pone.0088091

Retamal, R., Zaviezo, T., Malausa, T., Fauvergue, X., Le, G. I., and Toleubayev, K. (2016). Genetic analyses and occurrence of diploid males in field and laboratory populations of Mastrus ridens (Hymenoptera: Ichneumonidae), a parasitoid of the codling moth. Biol. Control 101, 69-77. doi: 10.1016/j.biocontrol.2016. 06.009

Rollins, L. A., Woolnough, A. P., Wilton, A. N., Sinclair, R., and Sherwin, W. B. (2009). Invasive species can't cover their tracks: using microsatellites to assist management of starling (Sturnus vulgaris) populations in Western Australia. Mol. Ecol. 18, 1560-1573. doi: 10.1111/j.1365-294x.2009.04132.x

Rousset, F. (2008). Genepop'007: a complete reimplementation of the Genepop software for Windows and Linux. Mol. Ecol. Resour. 8, 103-106. doi: 10.1111/j. 1471-8286.2007.01931.x

Roux, L. J., and Wieczorek, A. M. (2009). Molecular systematics and population genetics of biological invasions: towards a better understanding of invasive species management. Ann. Appl. Biol. 154, 1-17. doi: 10.1111/j.1744-7348.2008. 00280.x
Sakai, A. K., Allendorf, F. W., Holt, J. S., Lodge, D. M., Molofsky, J., With, K. A., et al. (2001). The population biology of invasive species. Ann. Rev. Ecol. Syst. 32, 305-332.

Schemerhorn, B. J., Crane, Y. M., Cambron, S. E., Crane, C. F., and Shukle, R. H. (2015). Use of microsatellite and SNP markers for biotype characterization in Hessian fly. J. Insect Sci. 15:158. doi: 10.1093/jisesa/iev138

Shang, X. P., Yao, Y. X., Huai, W. X., and Zhao, W. X. (2016). Effects of sample size on genetic diversity index for population of Obolodiplosis robiniae in use of microsatellite DNA marker. Plant Quar. 1, 32-35.

Shang, X. P., Yao, Y. X., and Zhao, W. X. (2015a). Geographic distribution of an invasive insect pest,Obolodiplosis robiniae (Diptera: Cecidomyiidae) in China. For. Pest Dis. 34, 33-36.

Shang, X. P., Yao, Y. X., Huai, W. X., and Zhao, W. X. (2015b). Population genetic differentiation of the black locust gall midge Obolodiplosis robiniae (Haldeman) (Diptera: Cecidomyiidae): a North American pest invading Asia. Bull. Entomol. Res. 105, 736-742. doi: 10.1017/s000748531500070x

Shao, X. K., Ma, X. G., Shao, K. F., Lv, J., and Han, G. S. (2010). Occurrence, damage and control of Obolodiplosis robiniae. J. Liaon. For. Sci. Technol. 4, 31-32.

Sharma, P. C., Grover, A., and Kahl, G. (2007). Mining microsatellites in eukaryotic genomes. Trends Biotechnol. 25, 490-498. doi: 10.1016/j.tibtech.2007.07.013

Shine, R., Brown, G. P., and Phillips, B. L. (2011). An evolutionary process that assembles phenotypes through space rather than through time. Proc. Natl. Acad. Sci. U.S.A. 108, 5708-5711. doi: 10.1073/pnas.1018989108

Simberloff, D., Martin, J. L., Genovesi, P., Maris, V., Wardle, D. A., Aronson, J., et al. (2013). Impacts of biological invasions: what's what and the way forward. Trends Ecol. Evol. 28, 58-66. doi: 10.1016/j.tree.2012.07.013

Simonato, M., Pilati, M., Magnoux, E., Courtin, C., Sauné, L., Rousselet, J., et al. (2019). A population genetic study of the egg parasitoid Baryscapus servadeii reveals large scale automictic parthenogenesis and almost fixed homozygosity. Biol. Control 139:104097. doi: 10.1016/j.biocontrol.2019.104097

Stalazs, A. (2014). New records of some dipterans (Diptera: Cecidomyidae, Tephritidae) in north-eastern Lithuania. Zool. Ecol. 24, 55-57.

Suarez, A. V., and Tsutsui, N. D. (2008). The evolutionary consequences of biological invasions. Mol. Ecol. 17, 351-360. doi: 10.1111/j.1365-294X.2007. 03456.x

Tsutsui, N. D., Suarez, A. V., and Grosberg, R. K. (2003). Genetic diversity, asymmetrical aggression, and recognition in a widespread invasive species. Proc. Natl. Acad. Sci. U.S.A. 100, 1078-1083. doi: 10.1073/pnas.023441 2100

Varshney, R. K., Chabane, K., Hendre, P. S., Aggarwal, R. K., and Graner, A. (2007). Comparative assessment of EST-SSR, EST-SNP and AFLP markers for evaluation of genetic diversity and conservation of genetic resources using wild, cultivated and elite barleys. Plant Sci. 173, 638-649. doi: 10.1016/j.plantsci. 2007.08.010

Wang, G. Y. (2009). Primary Study on Biology, Ecology and Chemical Control of Obolodiplosis robiniae. Master's dissertation, Shangdong Agriculture University, Taian.

Wu, N. N., Zhang, S. F., Li, X. W., Cao, Y. H., Liu, X. J., Wang, Q. H., et al. (2019). Fall webworm genomes yield insights into rapid adaptation of invasive species. Nat. Ecol. Evol. 3, 105-115. doi: 10.1038/s41559-018-0746-5

Xu, X. Q., and Yang, M. S. (2006). Review on utilization of Robinia pseudoacacia. J. Hebei For. Sci. Technol. S1:54.

Yang, Z. Q., Qiao, X. R., Bu, W. J., Yao, Y. X., Xiao, Y., and Han, Y. S. (2006). First discovery of an important invasive insect pest, Obolodiplosis robiniae (Diptera: Cecidomyiidae) in China. Acta Entomol. Sin. 49, 1050-1053.

Yao, Y. X., Zhao, W. X., and Shang, X. P. (2015). Development of polymorphic microsatellite markers of Obolodiplosis robiniae (Haldeman) (Diptera: Cecidomyiidae), a North American pest invading Asia. J. Insect Sci. 15:127. doi: 10.1093/jisesa/iev104

Yeh, F. C., Yang, R. C., Boyle, T. B. J., Ye, Z. H., and Mao, J. X. (2018). POPGENE, the User-Friendly Shareware for Population Genetic Analysis. Available at: http://wanfang.bjast.com.cn/D/ExternalResourceswdyx200204012\%5E45.aspx, (accessed November 10, 2018).

Zalewski, A., Michalska-Parda, A., Bartoszewicz, M., Kozakiewicz, M., and Brzeziński, M. (2010). Multiple introductions determine the genetic structure of an invasive species population: American mink Neovison vison in Poland. Biol. Conserv. 143, 1355-1363. doi: 10.1016/j.biocon.2010.03.009

Zeisset, I., and Beebee, T. J. C. (2003). Population genetics of a successful invader: the marsh frog Rana ridibunda in Britain. Mol. Ecol. 12, 639-646. doi: 10.1046/ j.1365-294x.2003.01775.x 
Zhao, S. Y., Sun, S. G., Dai, C., Gituru, R. W., Chen, J. M., Wang, Q. F., et al. (2015). Genetic variation and structure in native and invasive Solidago canadensis populations. Weed Res. 55, 163-172.

Zhou, Z. X., Wan, F. H., Zhang, G. F., and Chen, B. (2007). A rapid method for extraction of genomic DNA of Bemisia tabaci. Plant Protect. 33, 131-133. doi: 10.3390/genes10090632

Zong, J. W., Zhao, T. T., Ma, Q. H., Liang, L. S., and Wang, G. X. (2015). Assessment of genetic diversity and population genetic structure of Corylus mandshurica in China using SSR markers. PLoS One 10:e0137528. doi: 10.1371/journal.pone. 0137528
Conflict of Interest: The authors declare that the research was conducted in the absence of any commercial or financial relationships that could be construed as a potential conflict of interest.

Copyright (c) 2020 Yao, Shang, Yang, Lin, Huai and Zhao. This is an open-access article distributed under the terms of the Creative Commons Attribution License (CC BY). The use, distribution or reproduction in other forums is permitted, provided the original author(s) and the copyright owner(s) are credited and that the original publication in this journal is cited, in accordance with accepted academic practice. No use, distribution or reproduction is permitted which does not comply with these terms. 